$\xi=-1$

\title{
The Development of Resistivity Equipment for Subsoil Investigation
}

\author{
Nattapon Jaisumroum \\ ASEAN Institute for Health Development, Mahidol University, Thailand \\ *Corresponding author E-mail: nattaponj89@gmail.com
}

\begin{abstract}
This research aimed to develop the resistivity equipment for a groundwater investigation using $2 \mathrm{D}$ electrical resistivity technique. $2 \mathrm{D}$ electrical resistivity measurement was carried out at one profile with 90 meters long at Soi Dao district in Chantaburi Province, Thailand, where most of the areas are quite mountainous and longan plantation. Wenner electrode array was selected for 2D electrical resistivity measurement. The results showed that the instrument could be used to measure subsoil resistivity by using less capital cost with more convenient by weight and size and higher efficiency in depth measurement due to the higher voltage.
\end{abstract}

Keywords: Exploration, Resistivity, Subsoil, Soil Resistivity, Site exploration, Groundwater Investigation

\section{Introduction}

Geophysics is the study of subsurface investigation; the sequence and physical positions of lithological units, groundwater, and soil and rock strength parameters. Civil engineering mainly uses drilling method to determine average soil and rock strength and use the samples to represent the whole construction area which is costly and may not the accuracy representative. The resistivity method was developed to determine underlying geologic structure for less cost and time and was widely used to determine soil type and thickness, old tunnel, cavity, pipe and cable line, groundwater level, slippage. The goals of this paper are (1) to develop resistivity equipment for subsoil investigation with less cost and higher efficiency (2) to develop the prototype of equipment and software (3) to investigate groundwater for farmers at Soi Dao district in Chantaburi Province, Thailand.

\section{Basic Principles of the Resistivity Method}

\section{A. Basic principle of the electrical resistivity}

The relationships between the electrical resistivity, current and the electrical potential are governed by Ohm's law, which can be used to calculate the potential in a continuous medium.

$$
\frac{V}{I}=R=\rho \frac{L}{A}=\rho_{a} \frac{L}{A}
$$

Where, $\rho$ is the resistivity. $\rho_{a}$ is the apparent resistivity. $I$ is the current through the conductor in units of amperes, $V$ is the voltage measured across the conductor in units of volts, $R$ is the resistance of the conductor in units of ohms, $L$ is the length in units of meter and $A$ is the cross-sectional area in units of square meter.
The purpose of the resistivity method is to calculate the electrical resistivity of the subsoil, which is an unknown quantity. The basic data from a resistivity survey are the positions of the current and potential electrodes, the current, $I$, injected into the ground and the resulting voltage difference, $V$, between the potential electrodes. The current and voltage measurements are converted into an apparent resistivity, $\rho_{\mathrm{a}}$, value show in Figure 1.

$\rho_{a}=k \frac{\Delta V}{I}$

Where, $k$ is the geometric factor that depends on the configuration of the current and potential electrodes.

\section{B. Electrode Array}

An electrode array is a configuration of electrodes used for measuring either an electric current or voltage. Some electrode arrays can use to provide a stimulating pattern of electric current or voltage. In Civil engineering using ASTM D6431-99 standard, which

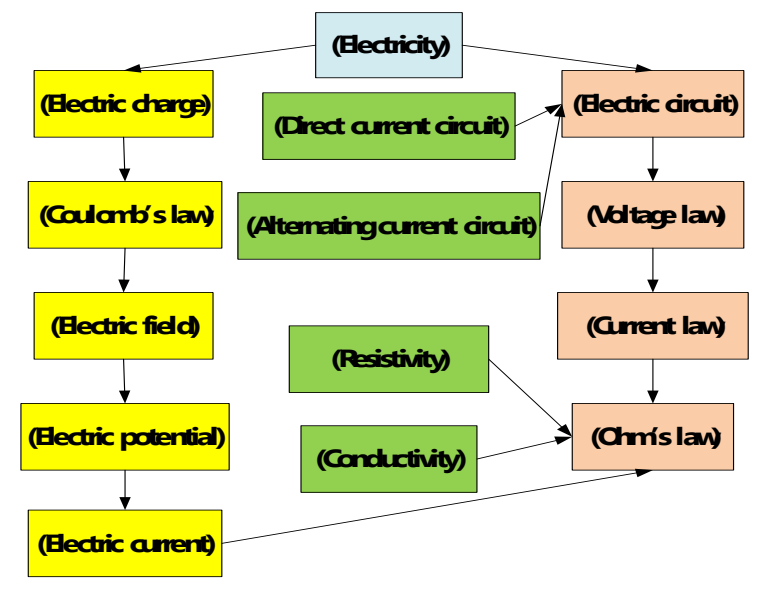


Fig. 1: Basic Principle of the Electrical Resistance Investigation.

\begin{tabular}{|l|c|c|c|}
\hline Specific characteristic & Wenner & $\begin{array}{c}\text { Schlum } \\
\text { berger }\end{array}$ & $\begin{array}{c}\text { Dipole- } \\
\text { dipole }\end{array}$ \\
\hline $\begin{array}{l}\text { Subsurface horizontal } \\
\text { investigation }\end{array}$ & ++++ & ++ & + \\
\hline $\begin{array}{l}\text { Subsurface Vertical } \\
\text { investigation }\end{array}$ & + & ++ & ++++ \\
\hline Depth of investigation & + & ++ & +++ \\
\hline $\begin{array}{l}\text { Extensive horizontal } \\
\text { data }\end{array}$ & + & ++ & +++ \\
\hline Signal stability & ++++ & +++ & + \\
\hline
\end{tabular}

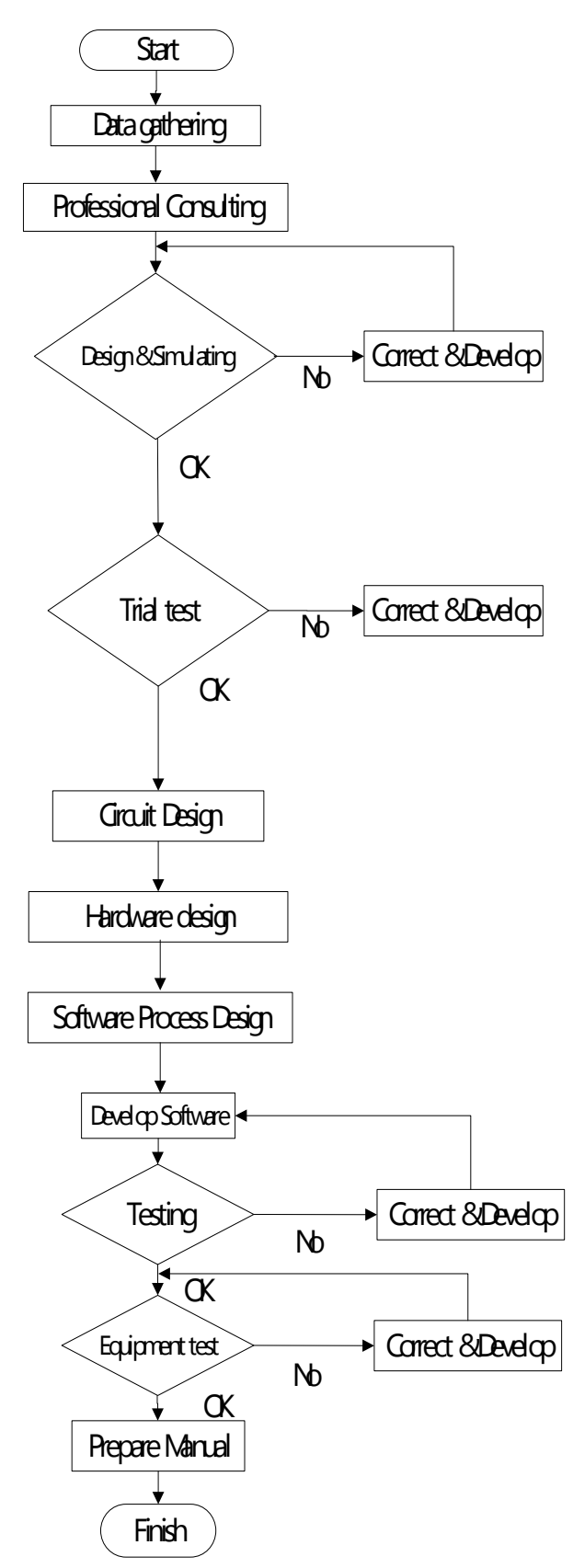

Fig. 2: Project Design Procedure

1. Electronic circuit design: process equipment design with software controller and interpretation programme shown in Figure 2.

\section{The Model}

\section{A. Design and quality control of the equipment}

2. 2. CRU-Resistivity Meter design: overall portable equipment 3. design shown in Figure 3. 


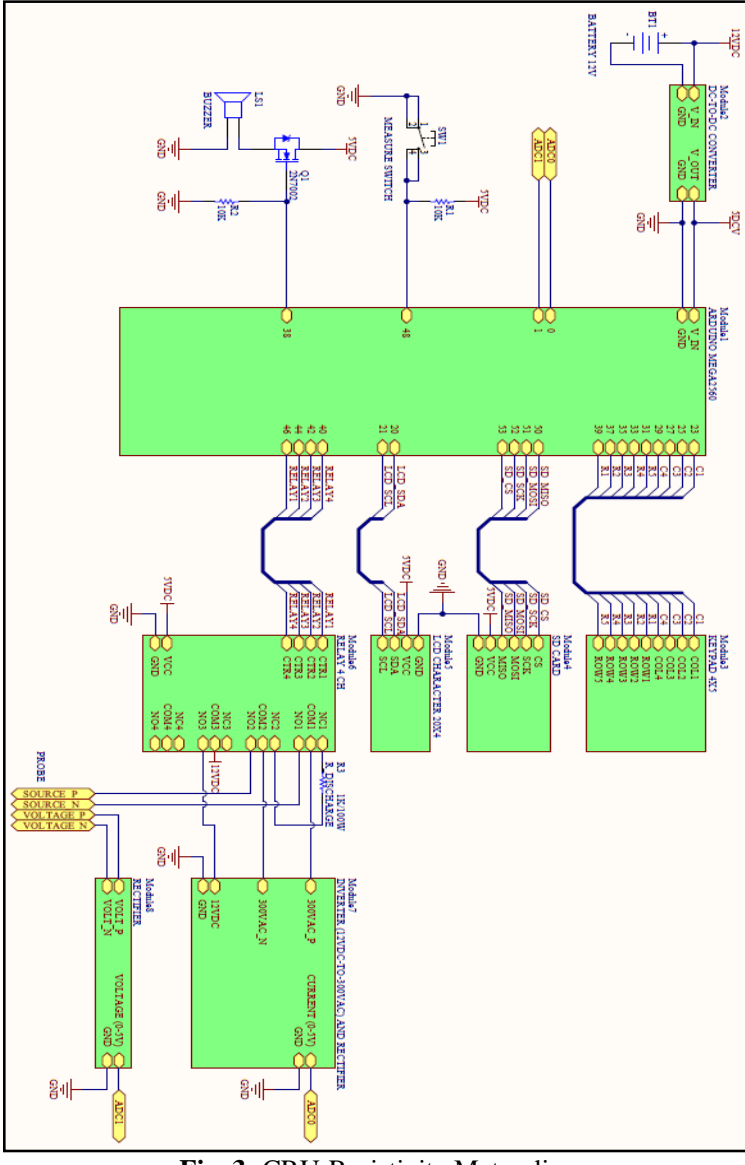

Fig. 3: CRU-Resistivity Meter diagram

3. Interface design: design interface programming between equipment and interpretation programme shown in Figure 4.

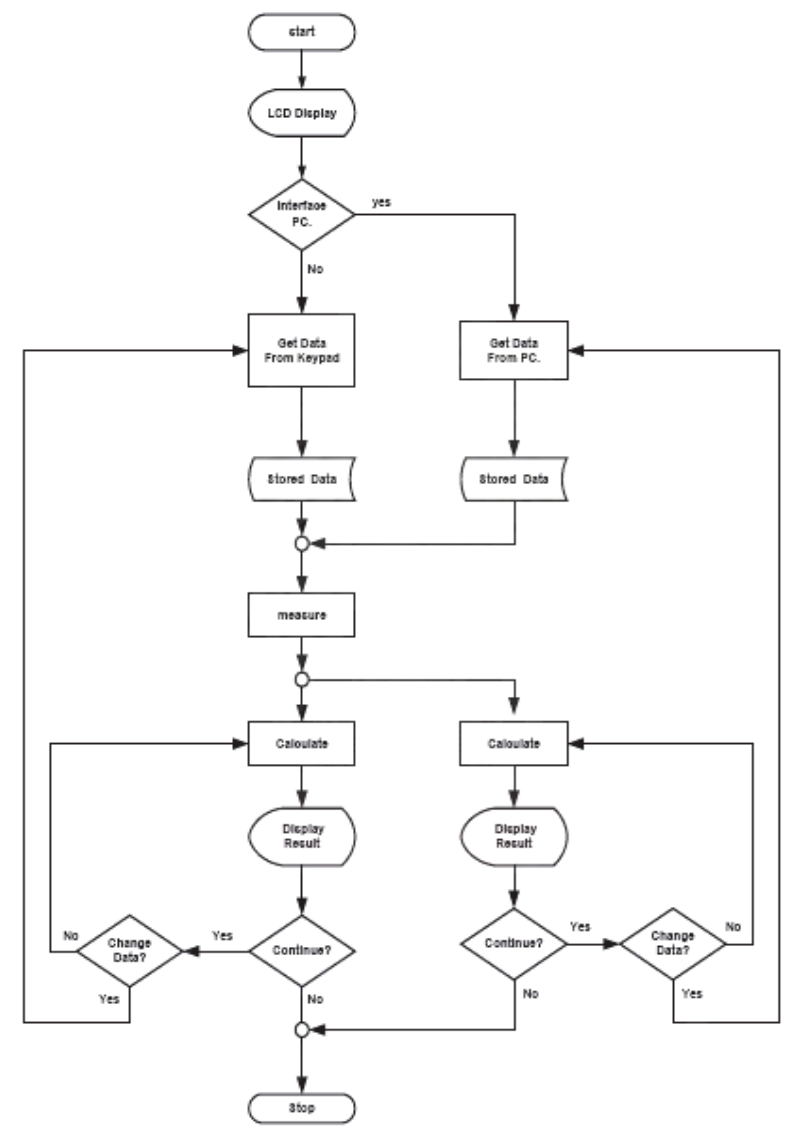

Fig. 4: Programming flowchart 4. Data Transmission: microcontroller processing using $4 \times 4$ metric via mouse and keyboard with LCD monitoring shown Figure 5.

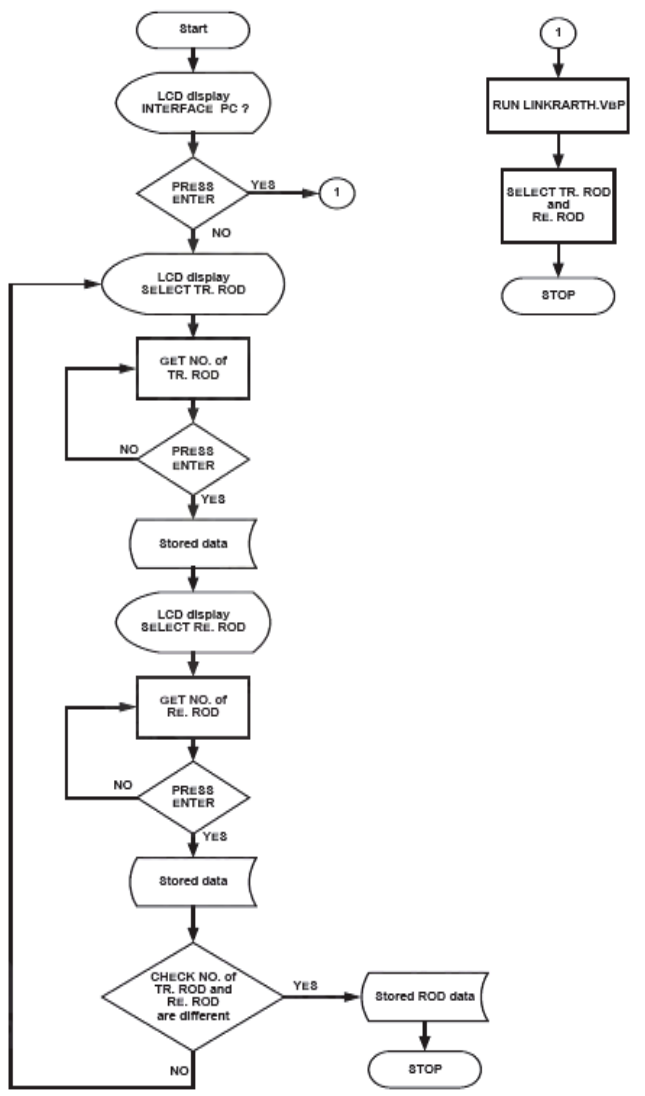

Fig. 5: Data transmission flowchart

5. Programming: microcontroller process receive command set via software controller as multi-logic to control electronic circuits shown in Figure 6.

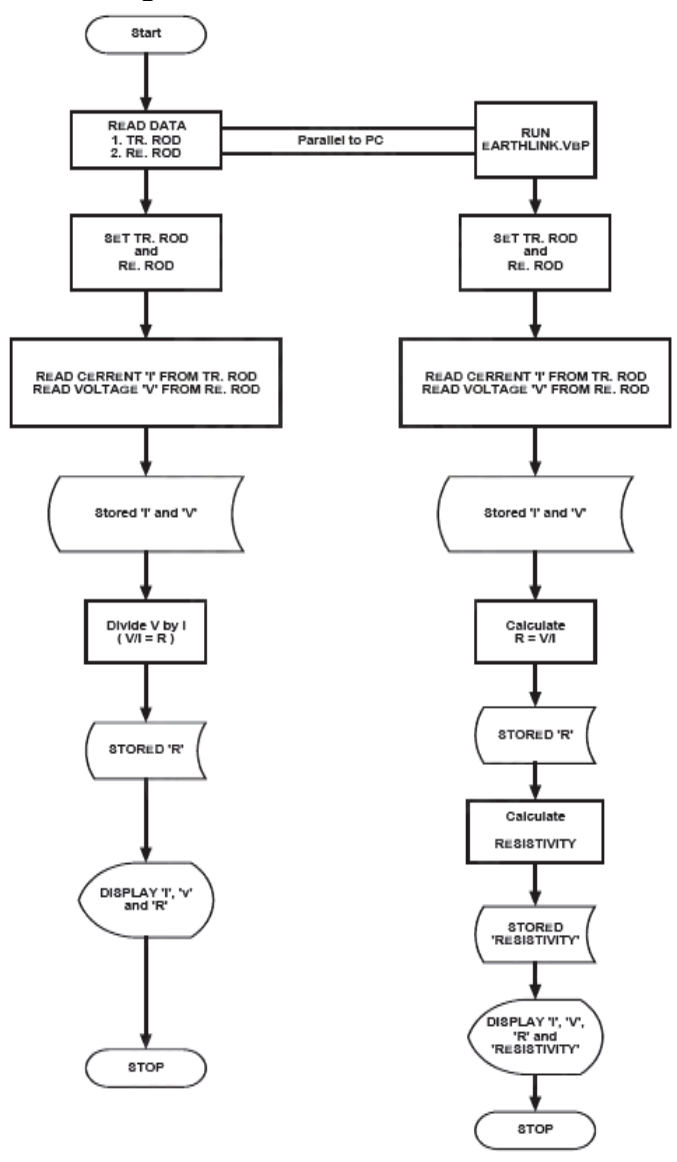

Fig. 6: Software controller flowchart

B. Field equipment 
1. CRU-Resistivity Meter: built in A. Design and quality control of the equipment shown in Figure 7.

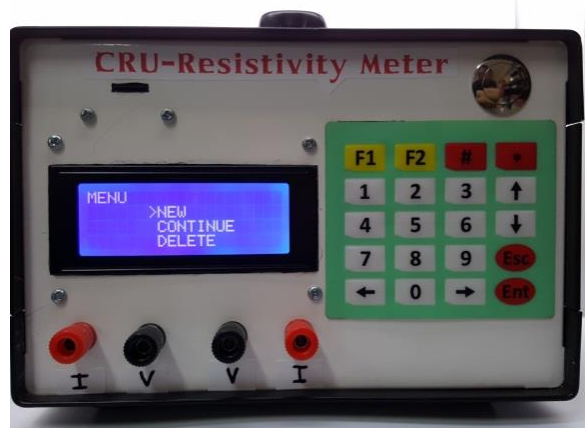

Fig. 7: CRU-Resistivity Meter

2. Copper rod: 4 piece of 1 centimeter diameter with 50 centimeters long, for transmitting current and measure differential voltage shown in Figure 8.

3. Wire: 1 square millimetre Stranded copper wire, maximum 14 amperes and 750 voltages, $1 \mathrm{ohm}$ per 100 -meter resistance.

4. Computer notebook for processing.

5. Battery 12 Volts dry cell: convenient mobility and the high temperature of the cell did not effect to the electric circuit.

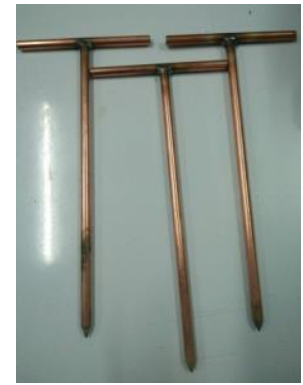

Fig. 8: Copper rod

\section{Data Analysis and Result}

The project was carried out with total spread of 90 meters long at Soi Dao district in Chantaburi, Thailand using Wenner array, as shown in Figure 9.
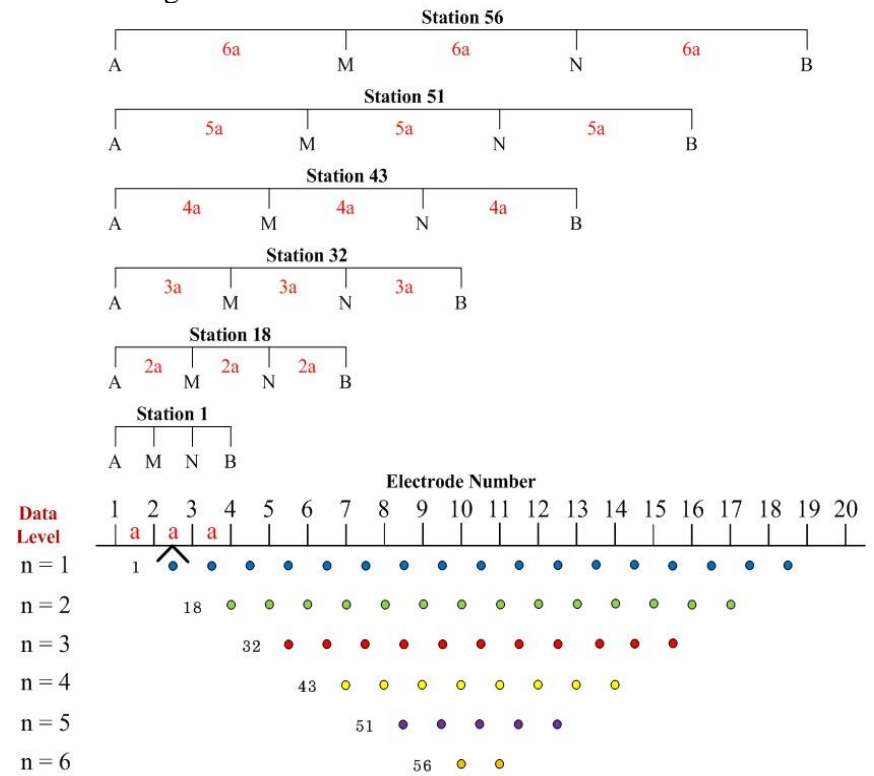

Fig. 9: Wenner Array

The result showed that the groundwater resistivity (15-90 ohms-meter) was lay at depth below 15 meter and good at below 23.4 meter, as shown in Figure 10.

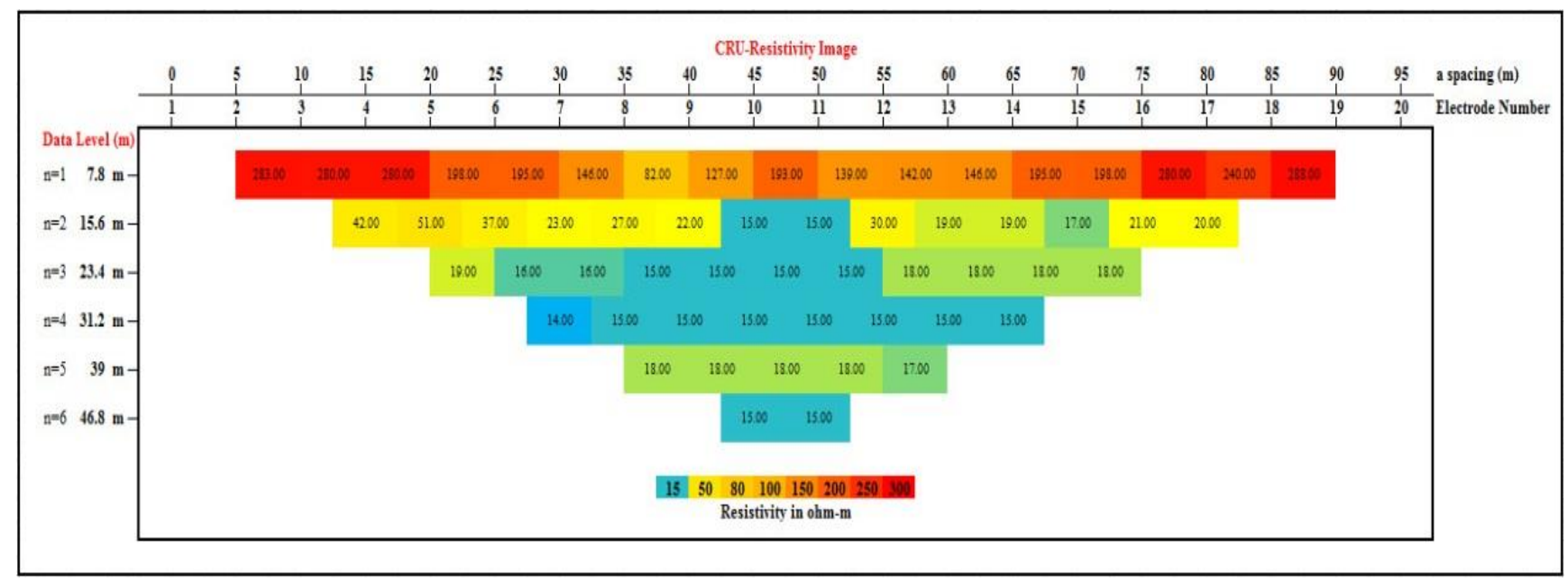

Fig. 10: Geophysics pseudo cross section obtained using CRU-Resistivity image program

One (1) well was planned at $13.1173 \mathrm{~N}, 102.28189 \mathrm{E}$ at 132.2 meter above mean sea level with target depth of 25 meter below ground level shown in Figure 11. After drilling shown in Figure 12 and 13, the groundwater showed at 22.5 meter below ground level which corresponding to the CRU-Resistivity program. 


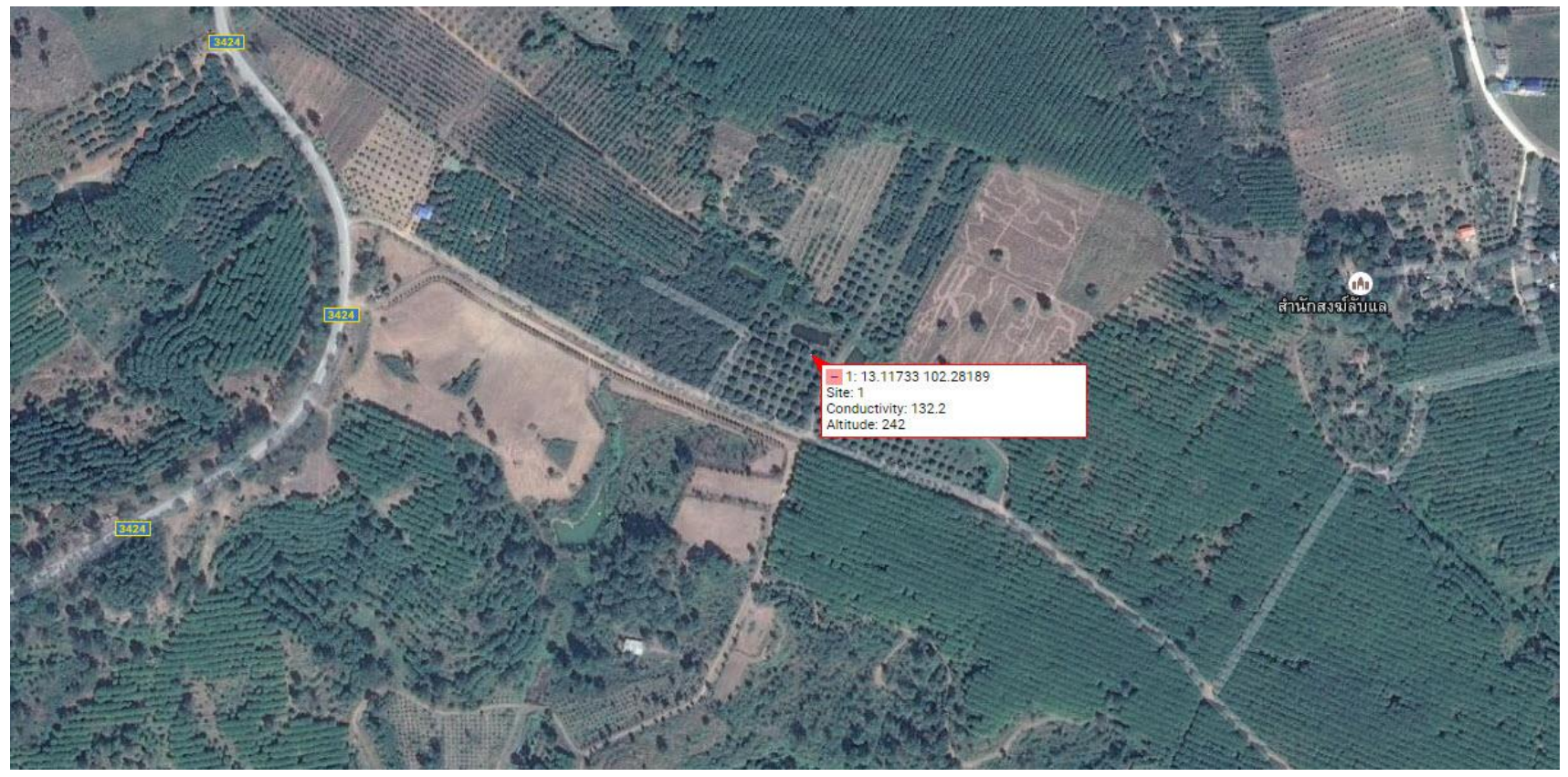

Fig. 11: Groundwater well at Soi Dao district in Chantaburi, Thailand

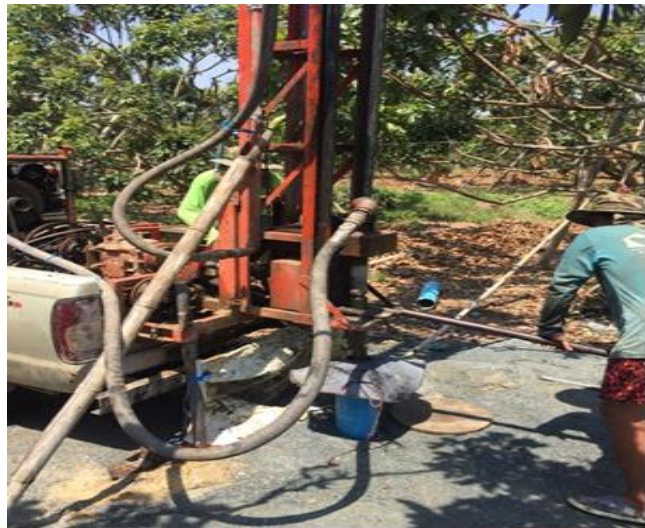

Fig. 12: Groundwater drilling rig

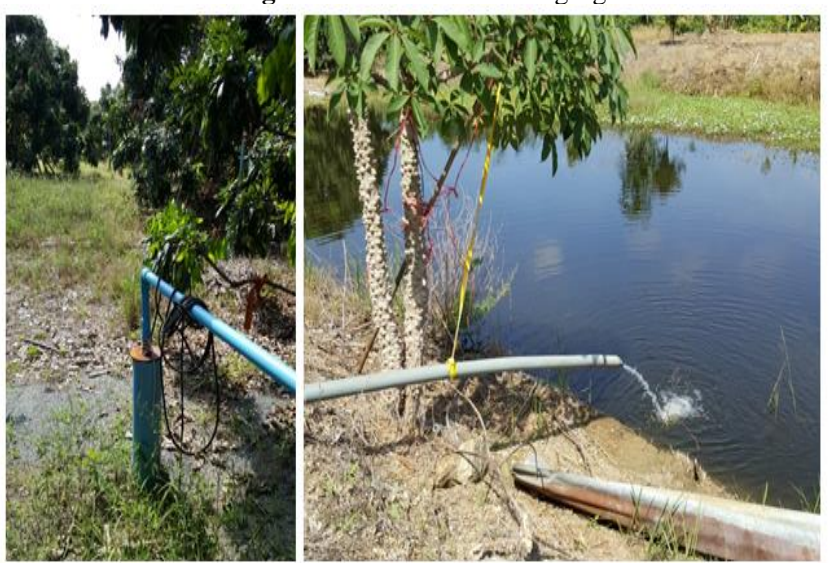

Fig. 13: Groundwater well

\section{Conclusion}

The CRU-Resistivity meter developed in this project was intended to develop the quality of life for the people in drought area to have more effective groundwater drilling well with fewer budgets. The result shows the good efficiency in both measurement and interpretation. The cost effectively reduced with more convenient by weight and the equipment can be replaced the commercial equipment in groundwater investigation size shown in Table 2.
Table 2: Equipment Capability

\begin{tabular}{|c|c|c|}
\hline Property & $\begin{array}{c}\text { Developed CRU } \\
\text { Resistivity Meter }\end{array}$ & $\begin{array}{c}\text { Available in the } \\
\text { market }\end{array}$ \\
\hline Price & 6,000 USD & 180,000 USD \\
\hline Voltage & 300 Volt & 220 Volt \\
\hline Size & $200 \times 280 \times 140 \mathrm{~mm}$ & $300 \times 325 \times 105 \mathrm{~mm}$ \\
\hline Weight & $3.2 \mathrm{~kg}$ & $5.2 \mathrm{~kg}$ \\
\hline
\end{tabular}

\section{Acknowledgement}

This study was supported scholarship by ASEAN Institute for Health Development, Mahidol University and we also thank anonymous reviewers and colleagues who have given valuable comments to improve quality of this paper.

\section{References}

[1] Prasan Taweewannakij, "Design and Construction of a Soil Sounding Instrument", M. Eng. thesis, Chulalongkorn University, Bangkok, Thailand, 2001.

[2] Adli, Z. H., Musa, M. H. and Khairul Arifin, M. N., "Electrical resistivity of subsurface: field and laboratory assessment". Engineering and Technology: 45, p. 799-802, 2010.

[3] (1983) IEEE Guide for Measureing Earth Resistivity, Ground Impedance, and Earth Surface Potential of a Ground System. ANSI/IEEE Std. 81-1983 (Revision of IEEE Std. 81-1962). New York : USA.

[4] Lateef, T. A., "Geophysical Investigation for Groundwater Using Electrical Resistivity Method - A Case Study Of Annunciation Grammar School, Ikere Lga, Ekiti State, South-Western Nigeria". Journal of Applied Physics: 2, p. 1-6, 2012.

[5] Omowumi, O., "Electrical resistivity imaging survey for shallow site investigation at university of Ibadan campus southwestern Nigeria". Journal of Engineering and Applied Sciences: 7, p. 187-196, 2012.

[6] Orfanos, C. and Apostolopoulos, G., "Analysis of different geophysical methods in the detection of an underground opening at a controlled test site". Journal of the balkan geophysical society: 15 , p. 7-18, 2012.

[7] Osazuwa, I. B. and Chii Chii, E., "Two-dimensional electrical resistivity survey around the periphery of an artificial lake in the precambrian basement complex of northern Nigeria". International Journal of Physical Sciences: 5, p. 238-245, 2010. 
[8] Telford, W. M., Geldart, L. P., and Sheriff, R. E., Applied geophysics. Cambridge : Cambridge University Press, 1990.

[9] Toll, D. G. and Hassan, A., "Data Acquisition and Control Software for Automated Resistivity Measurements". Information Technology in Geo-Engineering, p. 170-176, 2014. 